\title{
Gene floR e a resistência ao florfenicol em isolados de Aeromonas spp. autóctones de organismos aquáticos ${ }^{1}$
}

\author{
Naedja C.S.L. Silva ${ }^{2 *}$, Joel F. Nogueira ${ }^{3}$, João J.S. Gouveia ${ }^{3}$, Mateus M. Costa ${ }^{2}$ \\ and Gisele V. Gouveia ${ }^{2}$
}

\begin{abstract}
Silva N.C.S.L., Nogueira J.F., Gouveia J.J.S., Costa M.M. \& Gouveia G.V. 2018. [Gene floR and resistance to florfenicol in isolated Aeromonas spp. indigenous aquatic organisms.] Gene floR e a resistência ao florfenicol em isolados de Aeromonas spp. autóctones de organismos aquáticos. Pesquisa Veterinária Brasileira 38(3):357-366. Laboratório de Microbiologia e Imunologia, Universidade Federal do Vale do São Francisco, Rodovia BR-407 Km 12, Lote 543, Projeto de Irrigação Nilo Coelho s/n, C1, Petrolina, PE 56300-000, Brazil. E-mail: naedjacarla@gmail.com

The floR gene is described in related literature as responsible for resistance to florfenicol, which is a widely used antimicrobial agent in aquaculture. This gene has been reported in many species of bacteria, including the genus Aeromonas. These bacteria cause high mortality in fish farming bringing economic losses. It is important that studies of this gene and possible mutations that can lead to changes in the structure and function of the protein. The aim of this study was to characterize the floR gene in isolates of Aeromonas spp. and check if the presence of this gene is associated with resistance to florfenicol in Aeromonas spp. obtained from the San Francisco Valley. PCR (Polymerase Chain Reaction) were also performed to verify the presence of the floR gene in 27 isolates of Aeromonas spp. Positive samples for the presence of the gene were sequenced and analyzed for the presence of polymorphisms using alignments. Different haplotypes detected were used for analysis with the SIFT and PolyPhen programs for prediction of changes in protein function. The structural modeling of protein encoded by the $f l o R$ gene was performed using the Modeller software, and the models were evaluated by Procheck, Verify3D and Whatif. The similarity of the dimensional structure of reference protein with the dimensional structures of the proteins encoded by the different haplotypes was compared by TM-align. Bacterial resistance to florfenicol was assessed by the microdilution test, which was also performed in the presence of carbonyl cyanide m-chlorophenyl hydrazone to verify the effect of inhibiting the efflux pump. 14 isolates were positive for the presence of $f l o R$ gene and 10 were sequenced and allowed the identification of three polymorphisms in the floR gene, which led to construction of three different haplotypes (TAA TTA and CTG). The analyzes carried out with the SIFT and PolyPhen programs showed that the TTA and TAA haplotypes could probably change the protein structure-function. Proteins modeled for the three haplotypes were found to have substantially the same structural conformation with each other. All isolates presenting the gene were resistant to florfenicol and those who did not have were sensitive. The test in the presence of carbonyl cyanide m-chlorophenylhydrazone was conducted for three isolates, representing each single haplotype and was observed inhibition of bacterial growth at all concentrations independent of the haplotype. The results of this study show that resistance to flofenicol in Aeromonas spp. may be explained by the presence of floR gene and that this gene is associated with an efflux pump. Mutations observed in floR gene do not appear to be involved with chenges in structure and function of the protein encoded by gene. INDEX TERMS: FloR gene, florfenicol, Aeromonas spp., aquatic organisms, polymorphisms, protein structure and function, antimicrobial resistance, poikilotherm animals, bacterioses.
\end{abstract}

\footnotetext{
${ }^{1}$ Recebido em 22 de junho de 2016.

Aceito para publicação em 24 de novembro de 2016

Pesquisa de mestrado com apoio da FACEPE.

${ }^{2}$ Laboratório de Microbiologia e Imunologia, Universidade Federal do Vale do São Francisco, Rodovia BR-407 Km 12, Lote 543, Projeto de Irrigação Nilo Coelho s/n, C1, Petrolina, PE 56300-000, Brasil. E-mails:
}

mmatiuzzi@hotmail.com, gisele.veneroni@univasf.edu.br; *Autor para correspondência: naedjacarla@gmail.com

${ }^{3}$ Laboratório de Genética e Biotecnologia, Universidade Federal do Vale do São Francisco, Rodovia BR-407 Km 12, Lote 543, Projeto de Irrigação Nilo Coelho s/n, C1, Petrolina, PE 56300-000. 
RESUMO.- $O$ gene floR descrito é descrito pela literatura como o responsável pela resistência ao florfenicol, que é um antimicrobiano amplamente utilizado na aquicultura. Esse gene já foi relatado em muitas espécies de bactérias, inclusive no gênero Aeromonas. Essas bactérias causam alta mortalidade na piscicultura trazendo prejuízos econômicos. É importante que haja estudos sobre esse gene e possíveis mutações que possam levar a alterações na estrutura e função da proteína. Os objetivos desse estudo foram caracterizar o gene floR em isolados de Aeromonas spp. obtidas do Vale do São Francisco e verificar se a presença desse gene está associada com a resistência ao florfenicol. Foram realizadas reações em cadeia da polimerase (PCR) para a presença do gene floR em 27 isolados de Aeromonas spp.. Amostras positivas para a presença do gene foram sequenciadas e analisadas quanto à presença de polimorfismos por meio de alinhamentos. Os diferentes haplótipos detectados foram utilizados para análises com os programas SIFT e PolyPhen para predição de alteração de função proteica. A modelagem estrutural da proteina codificada pelo gene floR foi realizada com o programa Modeller e, os modelos foram avaliados pelo Procheck, Verify3D e Whatif. A similaridade da estrutura tridimensional da proteína referência com as estruturas tridimensionais das proteínas codificadas pelos diferentes haplótipos foi comparada através do TM-align. A resistência das bactérias ao florfenicol foi avaliada através do teste de microdiluição em caldo, o qual também foi realizado na presença do carbonil cianeto $\mathrm{m}$-clorofenil hidrazona para verificar o efeito da inibição da bomba de efluxo sobre tal resistência. Dos vinte e sete isolados avaliados quanto a presença do gene floR, 14 isolados foram positivos e 10 foram sequenciados, 0 que permitiu a identificação de três polimorfismos no gene floR, que levaram a construção de três haplótipos diferentes (TAA, TTA e CTG). As análises realizadas com os programas SIFT e PolyPhen apontaram que os haplótipos TTA e TAA provavelmente poderiam alterar a estrutura e função da proteína. As proteínas modeladas para os três haplótipos demonstraram possuir praticamente a mesma conformação estrutural entre si. Todos os isolados que apresentaram o gene foram resistentes ao florfenicol e aqueles que não apresentavam foram sensíveis. 0 teste na presença do Carbonil Cianeto m-Clorofenil Hidrazona foi realizado para três isolados, cada isolado representando um haplótipo, sendo possível observar a inibição do crescimento bacteriano em todas as concentrações independente do haplótipo. Os resultados obtidos nesse estudo mostram que a resistência ao flofenicol em Aeromonas spp. pode ser explicada pela presença do gene $f l o R$, e que esse gene está relacionado com uma bomba de efluxo. As mutações verificadas no gene $f l o R$, parecem não estar envolvidas com alteração de estrutura e função da proteína codificada por esse gene.

TERMOS DE INDEXAÇÃO: Gene floR, florfenicol, Aeromonas spp., organismos aquáticos, polimorfismos, estrutura e função proteica, resistência antimicrobiana, tilápia, Orecohromis niloticus, pacamã, Lophiosilurus alexandri, animais poiquilotermos, bacterioses.

\section{INTRODUÇÃO}

Os peixes que são submetidos a criações intensivas estão mais predispostos a problemas relacionados com estresse do que os peixes no seu estado selvagem. Alto teor de matéria orgânica, baixo nível de oxigênio dissolvido na água, bem como o contato contínuo com indivíduos podem contribuir para o aumento da susceptibilidade dos peixes a infecções (Barton \& Iwama 1991, Dallaire-Dufresne et al. 2014).

Espécies de Aeromonas mesófilas, especialmente A. hydrophila, têm sido associadas à mortandade de peixes em todo o mundo, resultando em enormes perdas econômicas (Janda \& Abbott 2010). É conhecido que o gênero Aeromonas causa mortalidade significativa tanto em água doce quanto em água marinha (Beaz-Hidalgo \& Figueras 2013). Bactérias desse gênero podem ser isoladas a partir de todos os nichos ambientais onde existem ecossistemas bacterianos, tais como peixes, alimentos, animais de estimação, invertebrados aquáticos, pássaros, carrapatos, insetos e solos (Janda \& Abbott 2010).

Com o aumento do consumo de produtos da aquicultura, a possibilidade de humanos contraírem infecções zoonóticas pela manipulação ou ingestão destes produtos também aumenta, sendo que Aeromonas hydrophila, Edwardsiella tarda, Mycobacterium marinum, Streptococcus iniae, Vibrio vulnificus e V. damsela são patógenos que têm sido associados a surtos de doenças através do consumo de peixe (Haenen et al. 2013).

A piscicultura sofre atualmente graves perdas por causa de doenças infecciosas, e a evolução de cepas de bactérias à resistência pode ser ocasionada pela utilização de antimicrobianos, pesticidas e desinfetantes utilizados na prevenção de doenças e promoção do crescimento nessas criações (Pandiyan et al. 2013). A resistência bacteriana aos antimicrobianos pode vir através de uma variedade de mecanismos, tais como mutação genética e transferência horizontal de genes de resistência (Li et al. 2015).

Atualmente o florfenicol é um antimicrobiano bastante utilizado no tratamento de enfermidades na piscicultura (Fernández-Alarcón et al. 2010). 0 florfenicol é um antimicrobiano análogo fluorado do cloranfenicol e tianfenicol (Park et al. 2008). 0 cloranfenicol e o florfenicol representam inibidores altamente potentes de biossíntese de proteína bacteriana (Schwarz et al. 2004). Segundo Li et al. (2015), o uso abusivo de antimicrobianos na piscicultura faz com que as bactérias enfrentem forte pressão de seleção que pode levar a aquisição de resistência.

Gordon et al. (2008) fizeram o primeiro relato do gene floR (proteína de resistência ao florfenicol/cloranfenicol) em Aeromonas bestiarum. Esse gene confere resistência ao antimicrobiano florfenicol, que é amplamente utilizado na piscicultura no tratamento de enfermidades (Fernández-Alarcón et al. 2010). A resistência ao cloranfenicol e florfenicol entre Aeromonas spp. é identificada com bastante frequência (Piotrowska \& Popowska 2014).

Vários estudos relatam a presença do gene floR em bactérias mediando resistência ao florfenicol, como em Edwardsiella ictaluri (Welch et al. 2009), Escherichia coli (Du et al. 2004) e Samonella spp. (Doublet et al. 2004). Segundo Du et al. (2004) 0 gene floR está relacionado com a codificação de uma bomba de efluxo. A proteína codificada por esse gene pertence à família de sistemas de efluxo da Superfamília dos Facilitadores Majoritários (MFS) (Prosite 2016). Os sistemas de efluxo em bactérias protegem as células dos antibióticos por transportar ativamente os compostos para fora do citoplasma e/ou periplasma e limitar assim o seu acúmulo em seu local de ação (Lynch 2006). 
O presente estudo teve como objetivos caracterizar o gene floR em isolados de Aeromonas spp. obtidas do Vale do São Francisco e verificar se a presença desse gene está associada com a resistência ao florfenicol.

\section{MATERIAL E MÉTODOS}

Amostras. Foram utilizados 27 isolados de Aeromonas spp. provenientes da bacterioteca do laboratório de Microbiologia e Imunologia Animal do campus de Ciências Agrárias da UNIVASF, Petrolina/PE/Brasil. Esses isolados foram obtidos a partir do rim, tegumento, intestino e lesões de tilápias (Orecohromis niloticus) e pacamãs (Lophiosilurus alexandri) doentes. Os animais foram provenientes da Barragem de Sobradinho/BA (943'094,93"S/4082'38,27"0) e do Projeto Bebedouro da CODEVASF/PE ( $\left.9^{\circ} 06^{\prime} 50,93^{\prime \prime} \mathrm{S} / 40^{\circ} 18^{\prime} 724,56^{\prime \prime} 0\right)$. As coletas foram realizadas em 2008 e 2009. Esses isolados foram previamente caracterizados por meio de suas características morfológicas, tintoriais, bioquímicas (Quinn et al. 1994), e identificados através de restrição enzimática (Ghatak et al. 2007).

Extração de DNA genômico. Os DNAs dos isolados de Aeromonas spp. foram termo-extraídos em um volume final de $500 \mu \mathrm{l}$ e armazenado a $-20^{\circ} \mathrm{C}$ conforme Sá et al. (2013).

Genotipagem do gene floR. A presença do gene floR nos isolados de Aeromonas spp. foi avaliada por meio da Reação em Cadeia da Polimerase (PCR) com a utilização dos iniciadores floR1 (5'-CCCGCTATGATCCAACTCAC-3') e floR2 (5'-ACCCACATCGGTAGGATGAA-3') que amplificam um fragmento de 803 pb do referido gene (Gordon et al. 2008).

Na reação foram utilizados os seguintes reagentes: tampão de enzima 1x (10mM de Tris-HCl Ph 8,5; 50mM de KCl), 2,5mM de $\mathrm{MgCl}_{2}, 0,4 \mathrm{mM}$ de dNTPs, 0,6 $\mu \mathrm{M}$ de cada iniciador, 2,5U de Taq polimerase (Taq Platinum, Invitrogen ${ }^{\circledR}$ ) e $5 \mu \mathrm{L}$ de DNA molde em um volume final de $25 \mu \mathrm{L}$. Os ciclos de amplificação foram constituídos em termociclador (AMPLITHERM ${ }^{\circledR}$ ) com uma desnaturação inicial a $95^{\circ} \mathrm{C}$ por 5 minutos, seguido de 35 ciclos de desnaturação a $95^{\circ} \mathrm{C}$ por 1 minuto, anelamento específico do iniciador a $59^{\circ} \mathrm{C}$ por 45 segundos e extensão a $72^{\circ} \mathrm{C}$ por 1 minuto, seguido de uma extensão final a uma temperatura de $72^{\circ} \mathrm{C}$ por 5 minutos. Amostras com resultado negativo para a presença desse gene foram analisadas em duplicatas.

Os produtos de amplificação dos isolados foram visualizados em eletroforese em gel de agarose 1,5\% corado com brometo de etídeo a uma concentração de $0,01 \mathrm{~g} / \mathrm{mL}$.

Identificação de polimorfismos no gene floR. As amostras amplificadas para o floR foram purificadas em coluna de celulose (PureLink $^{\mathrm{TM}}$ Quick Gel Extraction and PCR Purification Combo Kit, Invitrogen ${ }^{\circledR}$ ) e enviadas para sequenciamento Sanger em empresa particular (HELIXXA ${ }^{\circledR}$-Bases for Life). As sequências obtidas foram analisadas pelo programa de base calling Phred (Ewing \& Green 1998, Ewing et al. 1998). Somente foram consideradas nas análises posteriores as sequências com alto valor de Phred (valor de Phred maior que 20). Em seguida, contigs foram montados com o programa CAP3 utilizando-se as sequências Foward e Reverse sequenciadas para cada amostra (Huang \& Madan 1999).

Os contigs obtidos foram alinhados contra uma sequência referência do gene floR oriunda de Aeromonas bestiarum (gi|148274163:979011004) obtida do banco de dados do Centro Nacional de Informações sobre Biotecnologia (NCBI 2016) para identificação de polimorfismos de base única (SNP). 0 alinhamento foi realizado por meio da utilização do programa CLUSTALW (Larkin et al. 2007), implementado no software MEGA6 (Tamura et al. 2011). Com base no alinhamento, foram identificados os sítios polimórficos em relação à sequência de referência e, haplótipos foram construídos para o conjunto de isolados analisados.

Predição de alteração de função da proteína codificada pelo gene floR em função da presença de polimorfismos no gene. Inicialmente procedeu-se com obtenção da sequência de aminoácidos codificada pelos diferentes haplótipos identificados. Para isso, utilizou-se o frame de leitura da sequência referência do gene floR (gi|148274163:9790-11004). Esta etapa foi realizada no software MEGA6. Para confirmar a correta tradução da sequência de nucleotídeos, as sequências traduzidas foram comparadas com as sequências de aminoácidos depositadas no banco de dados do NCBI para esse gene (YP_001220605.1, ABQ41442.1, DAA64637.1, WP_011931116.1).

Para predizer o efeito da alteração de aminoácidos na estrutura da proteína em função dos polimorfismos detectados, foram utilizados os programas SIFT (Ng \& Henikoff 2001) e Polyphen 2 (Adzhubei et al. 2010).

Modelagem da proteína codificada pelo gene floR. Nessa análise buscou-se verificar se os diferentes haplótipos identificados poderiam alterar a estrutura da proteína codificada pelo gene floR. Para isso, foram modeladas as proteínas codificadas pelos diferentes haplótipos identificados e a proteína codificada pelo gene referência (gi|148274163:9790-11004). Todas as análises foram realizadas individualmente para cada haplótipo e para o gene referência.

Para modelagem estrutural das proteínas foi utilizado o software Modeller (Sali \& Blundell 1993).

Pesquisas nos bancos de dados Blast-Protein (2015), Protein Data Bank (PDB 2016) e Swiss-Model (2015) permitiram a seleção de proteinas com estruturas tridimensionais resolvidas para serem ultilizadas como moldes, sendo selecionados os três moldes do PDB: 3wdo, 4lds e 4ja3. Os moldes 3wdo e 4ja3 são proteínas da família MFS e pertencem a Escherichia coli e o molde 4lds é também uma proteína da família MFS, mas pertence a um Staphylococcus epidermidis.

Para as análises da qualidade do modelo gerado para cada proteína modelada pelo MODELLER foram utilizados três softwares: PROCHECK (Laskowski et al.1993) que avalia a exatidão estereoquímica, WHATIF (Vriend \& Sander 1993) que avalia a qualidade do empacotamento e VERIFY3D (Bowie et al. 1991) que avalia a confiabilidade do enovelamento.

A similaridade da estrutura tridimensional da proteína referência (A. bestiarum) com as estruturas tridimensionais das proteínas codificadas pelos haplótipos foi comparada pelo software TM-align (Zhang \& Skolnick 2005) para predição de alteração estrutural em função dos diferentes haplótipos.

Análise da resistência dos isolados de Aeromonas spp. ao florfenicol. A resistência ao florfenicol pelos isolados de Aeromonas spp. foi verificada pelo teste de microdiluição em caldo.

0 teste foi realizado de acordo com o protocolo (CLSI 2014). A concentração bactericida mínima (CBM) do antimicrobiano foi determinada. 0 florfenicol (Sigma ${ }^{\circledR}$ ) primeiramente foi diluído em DMSO para que se fosse possível realizar o teste.

Os isolados foram replicados em TSA, incubados a $28^{\circ} \mathrm{C}$ por 24 horas e, após esse período foi realizada a suspensão bacteriana de acordo com a escala 0,5 de MacFarland (BioMeriéux, França). Esta suspensão foi obtida em tubos contendo solução salina estéril $0,85 \%$. A diluição final do antibiótico constou de $75 \mathrm{mg} / \mathrm{mL}, 37,5 \mathrm{mg} / \mathrm{mL}, 18,75 \mathrm{mg} / \mathrm{mL}, 9,37 \mathrm{mg} / \mathrm{mL}, 4,68 \mathrm{mg} / \mathrm{mL}$, $2,34 \mathrm{mg} / \mathrm{mL}, 1,17 \mathrm{mg} / \mathrm{mL}, 585 \mu \mathrm{g} / \mathrm{mL}, 292 \mu \mathrm{g} / \mathrm{mL}, 146 \mu \mathrm{g} / \mathrm{mL}$, $73,1 \mu \mathrm{g} / \mathrm{mL}, 36,56 \mu \mathrm{g} / \mathrm{mL} 18,2 \mu \mathrm{g} / \mathrm{mL}, 9,14 \mu \mathrm{g} / \mathrm{mL}, 4,57 \mu \mathrm{g} / \mathrm{mL}$, $2,28 \mu \mathrm{g} / \mathrm{mL}, 1,14 \mu \mathrm{g} / \mathrm{mL}, 0,57 \mu \mathrm{g} / \mathrm{mL}, 0,285 \mu \mathrm{g} / \mathrm{mL}, 0,142 \mu \mathrm{g} / \mathrm{mL}$, 
$0,071 \mu \mathrm{g} / \mathrm{mL}, 0,035 \mu \mathrm{g} / \mathrm{mL}, 0,017 \mu \mathrm{g} / \mathrm{mL}, 0,0085 \mu \mathrm{g} / \mathrm{mL}$, ao final totalizando 24 diluições.

As análises foram realizadas em triplicatas para cada isolado, sendo utilizado como controle negativo o caldo MH (sem florfenicol) e como controle positivo o caldo $\mathrm{MH}+$ bactéria (sem florfenicol), também foi realizado o controle do diluente (DMSO). Foi utilizada como controle no teste, a cepa de Escherichia coli ATCC (25922). A leitura da CBM foi realizada de acordo com o breakpoint do florfenicol de $4 \mu \mathrm{g} / \mathrm{ml}$ como descrito por Godoy et al. (2008).

Análise da resistência dos isolados de Aeromonas spp. ao florfenicol na presença do Carbonil Cianeto $\mathbf{m}$-Clorofenil Hidrazona (CCCP). A resistência ao florfenicol na presença do CCCP (inibidor de bomba de efluxo) pelos isolados de Aeromonas spp. foi verificada pelo teste de microdiluição em caldo. Foram utilizados três isolados referentes a cada haplótipo encontrado nesse estudo (TTA, TAA e CTG), os quais foram resistentes ao florfenicol.

Essa análise foi realizada com a utilização do teste de microdiluição em caldo, de acordo com o protocolo (CLSI, 2014), sendo a concentração bactericida mínima (CBM) do antimicrobiano determinada na presença do inibidor de bombas de efluxo. O florfenicol (Sigma ${ }^{\circledR}$ ) primeiramente foi diluído em DMSO para que fosse possível realizar o teste e o reagente CCCP foi diluído em acetona.

Os isolados foram replicados em TSA, incubados a $28^{\circ} \mathrm{C}$ por 24 horas e, após esse período foi realizada a suspensão bacteriana de acordo com a escala 0,5 de MacFarland (BioMeriéux, França). Esta suspensão foi obtida em tubos contendo solução salina estéril 0,85\%. A diluição final do antibiótico constou de $75 \mathrm{mg} / \mathrm{mL}, 37,5 \mathrm{mg} / \mathrm{mL}$, $18,75 \mathrm{mg} / \mathrm{mL}, 9,37 \mathrm{mg} / \mathrm{mL}, 4,68 \mathrm{mg} / \mathrm{mL}, 2,34 \mathrm{mg} / \mathrm{mL}, 1,17 \mathrm{mg} / \mathrm{mL}$, $585 \mu \mathrm{g} / \mathrm{mL}, 292 \mu \mathrm{g} / \mathrm{mL}, 146 \mu \mathrm{g} / \mathrm{mL}, 73,1 \mu \mathrm{g} / \mathrm{mL}, 36,56 \mu \mathrm{g} / \mathrm{mL} 18,2 \mu \mathrm{g} / \mathrm{mL}$, $9,14 \mu \mathrm{g} / \mathrm{mL}, 4,57 \mu \mathrm{g} / \mathrm{mL}, 2,28 \mu \mathrm{g} / \mathrm{mL}, 1,14 \mu \mathrm{g} / \mathrm{mL}, 0,57 \mu \mathrm{g} / \mathrm{mL}, 0,285 \mu \mathrm{g} / \mathrm{mL}$, $0,142 \mu \mathrm{g} / \mathrm{mL}, 0,071 \mu \mathrm{g} / \mathrm{mL}, 0,035 \mu \mathrm{g} / \mathrm{mL}, 0,017 \mu \mathrm{g} / \mathrm{mL}, 0,0085 \mu \mathrm{g} / \mathrm{mL}$ ao final totalizando 24 diluições. Foi adicionado $20 \mu \mathrm{L}$ do CCCP $(0,04 \mathrm{M})$ em cada poço.

As análises foram realizadas em triplicatas para cada isolado, sendo utilizado como controle negativo o caldo $\mathrm{MH}$ (sem florfenicol) e como controle positivo o caldo $\mathrm{MH}+$ bactéria (sem florfenicol), também foi realizado o controle do diluente do florfenicol e do CCCP (DMSO e acetona, respectivamente, acrescidos de bactéria).

\section{RESULTADOS E DISCUSSÃO}

\section{Presença do gene floR}

Vinte e sete isolados foram testados quanto a presença do gene $f l o R$, sendo que $14(58,33 \%)$ foram positivos quanto a presença desse gene. Esse resultado demonstra que os isolados vêm sofrendo seleção a favor da manutenção desse gene que confere resistência ao florfenicol. Essa alta incidência de isolados contendo a informação genética necessária para a manifestação da resistência a esse antibiótico pode servir de alerta aos produtores da região, pois em um futuro próximo a utilização desse antibiótico pode não ser mais efetiva no combate a esses patógenos. Verner-Jeffreys et al. (2009) em seu estudo detectaram a presença do gene floR em 16 dos 93 isolados de peixes ornamentais, dois desses isolados foram identificados como Aeromona hydrophila e Aeromona punctata, possuíam o gene floR e também apresentaram resistência ao cloranfenicol e florfenicol. 0 primeiro relato desse gene em Aeromonas foi na espécie $A$. bestiarum em 2008, quando Gordon et al. (2008) confirmaram que a resistência ao florfenicol era devido a presença do gene floR e que o mesmo poderia ser mediado por um plasmídeo que carreava também outros genes de resistência a antibióticos.

\section{Polimorfismos no gene floR}

Dentre as 14 amostras positivas para o gene floR, 10 tiveram porções desse gene sequenciadas. Com base no alinhamento das 10 sequências obtidas para o gene floR foram identificados três sítios polimórficos em relação à sequência de referência (A. bestiarum). 0 primeiro sítio consistiu na transição T-C na posição 479 do gene, o segundo sítio consistiu na transversão A-T na posição 683 e o terceiro sítio consistiu na transição G-A na posição 721. Diante disso, foi possível observar nos isolados a presença de três diferentes haplótipos (CTG, TAA, TTA) (Quadro 1). É bem relatado na literatura que as mutações, juntamente com a transferência horizontal de genes, são importantes mecanismos para o desenvolvimento de resistência em bactérias (Baym et al. 2016). Entretanto, muitas vezes uma única mutação não é suficiente para induzir uma alteração no perfil de sensibilidade das bactérias, como por exemplo, o que ocorre com as fluoroquinolonas (Jalal et al. 2000, Wang et al. 2001, Weigel et al. 2001, Vogwill \& Maclean 2015).

Os três sítios polimórficos identificados puderam ser classificados como mutações não sinônimas, ou seja, levaram à troca de aminoácidos na cadeia polipeptídica. O SNP_479 causa a troca de valina (V) para alanina (A) na posição 160 da cadeia polipeptídica, o SNP_683 ocasiona uma alteração de tirosina (Y) para fenilalanina (F) na posição 228 da cadeia polipeptídica e o SNP_721 leva a troca de uma glicina (G) para uma serina (S) na posição 241 da cadeia polipeptídica (Quadro 2).

Na literatura, ainda não foram encontrados relatos de estudos apresentando polimorfismos no gene floR. Polimorfismos de nucleotídeo único não sinônimos (nsSNPs), ocorrem em regiões codificadoras e resultam em polimorfismos de um único aminoácido (SAPs) com potencial para alterar a função da proteína através da alteração da sua estrutura (Capriotti \& Altman 2011). Os Polimorfismos de nucleotídeo único (SNPs) são de grande importância, porque essas alterações podem afetar a estabilidade das proteínas e complexos proteína-proteína (Teng et al. 2009). Um grande número de SNPs pode ser funcionalmente neutro, mas quando ocorrem em regiões codificantes e reguladoras podem causar efeitos deletérios sobre as funções das proteínas (Bao \& Cui 2005).

Quadro 1. Polimorfismos identificados nos isolados de Aeromonas hydrophila

\begin{tabular}{lcccc}
\hline \multicolumn{1}{c}{ Identificador } & SNP_479 & SNP_683 & SNP_721 & $\begin{array}{c}\text { Identificação do } \\
\text { haplótipo }\end{array}$ \\
\hline gi|148274163:979011004* & $\mathrm{T}$ & $\mathrm{A}$ & $\mathrm{G}$ & - \\
Isolado 35 & $\mathrm{C}$ & $\mathrm{T}$ & $\mathrm{G}$ & 479C_683T_721G \\
Isolado 11 & $\mathrm{C}$ & $\mathrm{T}$ & $\mathrm{G}$ & 479C_683T_721G \\
Isolado 15 & $\mathrm{C}$ & $\mathrm{T}$ & $\mathrm{G}$ & 479C_683T_721G \\
Isolado 22 & $\mathrm{C}$ & $\mathrm{T}$ & $\mathrm{G}$ & 479C_683T_721G \\
Isolado G36 & $\mathrm{C}$ & $\mathrm{T}$ & $\mathrm{G}$ & 479C_683T_721G \\
Isolado A10 & $\mathrm{T}$ & $\mathrm{A}$ & $\mathrm{A}$ & 479T_683A_721A \\
Isolado G38 & $\mathrm{T}$ & $\mathrm{A}$ & $\mathrm{A}$ & 479T_683A_721A \\
Isolado P16 & $\mathrm{T}$ & $\mathrm{A}$ & $\mathrm{A}$ & 479T_683A_721A \\
Isolado P22 & $\mathrm{T}$ & $\mathrm{A}$ & $\mathrm{A}$ & 479T_683A_721A \\
Isolado G4 & $\mathrm{T}$ & $\mathrm{T}$ & $\mathrm{A}$ & 479T_683T_721a \\
* gi|148274163:979011004 & sequência de referência de Aeromonas \\
bestiarium. & \multicolumn{4}{c}{}
\end{tabular}




\section{Predição de alteração de função da proteína codificada pelo gene floR}

O algoritmo SIFT utiliza sequências homólogas para prever se a substituição de um aminoácido afetará a função da proteína e, portanto, pode potencialmente alterar o fenótipo (Ng \& Henikoff 2003). Usando o programa SIFT nesse estudo, foi possível observar que a substituição na posição 160 de uma valina para uma alanina foi considerada como tolerante com uma pontuação de 1,00 , a substituição na posição 228 de uma fenilalanina para uma tirosina também foi considerada como tolerante com uma pontuação de 1,00 e, a substituição na posição 241 de uma glicina para uma serina foi prevista como tolerante com uma pontuação de 0,17 (Quadro 3).

De acordo com o SIFT valores inferiores a 0,05 são preditos como mutações intolerantes ou deletérias, já para valores superiores a 0,05 são preditas como tolerantes. A substituição na posição 241 teve uma pontuação mais baixa que as outras duas substituições nas posições 160 e 228, mas ainda foi considerada como tolerada.

O algoritmo PolyPhen classifica o SNP como "benigno", "possivelmente prejudicial" ou "provavelmente prejudicial " (Adzhubei et al. 2010). Os resultados obtidos nesse estudo mostraram que as mutações nas posições 228 (Fig. 1A) e 160 (Fig. 1B) foram consideradas benignas e que a mutação na posição 241 foi classificada como provavelmente prejudicial, isto é, tem chances dessa mutação provocar alguma alteração que ocasione ganho ou perda da função (Fig.1C) (Adzhubei et al. 2010).

De acordo com o Polyphen a troca de aminoácido na posição 241 pode levar a alguma alteração de ganho ou perda na função e, esse resultado pode ser explicado pela alteração de aminoácidos com propriedades químicas diferentes (Glicina/Serina), onde a glicina é apolar e não apresenta o carbono quiral e a serina é polar com presença de um cabono quiral. Para todos os aminoácidos comuns, exceto a glicina, o carbono $\alpha$ está ligado a quatro diferentes grupos: um grupo carboxila, um grupo amino, um grupo R e um átomo de hidrogênio (na glicina o grupo R é outro átomo de hidrogênio) (Lehninger 2006).

Muitos autores utilizam o SIFT e PolyPhen para predizer alteração de função proteica, principalmente em humanos, como em um estudo realizado por Goswami (2015), onde foram analisados 16 nsSNPs de um enzima envolvida na biossíntese de hormônios esteroides em humanos (HSD3B2) e, observou-se que segundo os algoritmos SIFT e PolyPhen, oito nsSNPs foram classificados como possivelmente prejudiciais

Quadro 2. Alterações de aminoácidos na cadeia polipeptídica segundo os polimorfismos detectados

\begin{tabular}{lcccc}
\hline \multicolumn{1}{c}{ Identificador } & Poplótipo & $\begin{array}{c}\text { Posção } \\
160 \\
\text { na } \\
\text { proteína }\end{array}$ & $\begin{array}{c}\text { Posição } \\
228 \\
\text { na } \\
\text { proteína }\end{array}$ & $\begin{array}{c}\text { Posição } \\
241 \\
\text { na } \\
\text { proteína }\end{array}$ \\
\hline gi|148274163:979011004* & TAG & Valina & Fenilalanina & Glicina \\
479C_683T_721G & CTG & Alanina & Tirosina & Glicina \\
479T_683A_721A & TAA & Valina & Fenilalanina & Serina \\
479T_683T_721A & TTA & Valina & Tirosina & Serina
\end{tabular}

* gi|148274163:979011004 = sequência de referência.

Quadro 3. Resultados referentes ao algorítimo SIFT na predição de alteração de função da proteína codificada pelo gene floR

\begin{tabular}{ccc}
$\begin{array}{c}\text { Posição do aminoácido } \\
\text { na proteína }\end{array}$ & Predição & Score \\
\hline 160 & Tolerante & 1,0 \\
228 & Tolerante & 1,0 \\
241 & Tolerante & 0,17
\end{tabular}

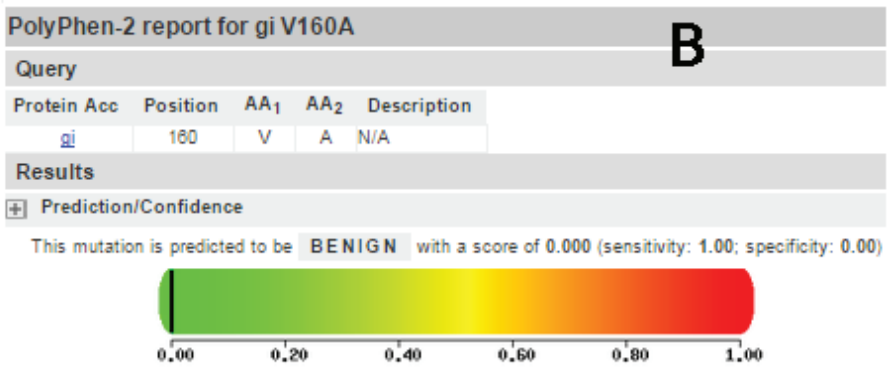

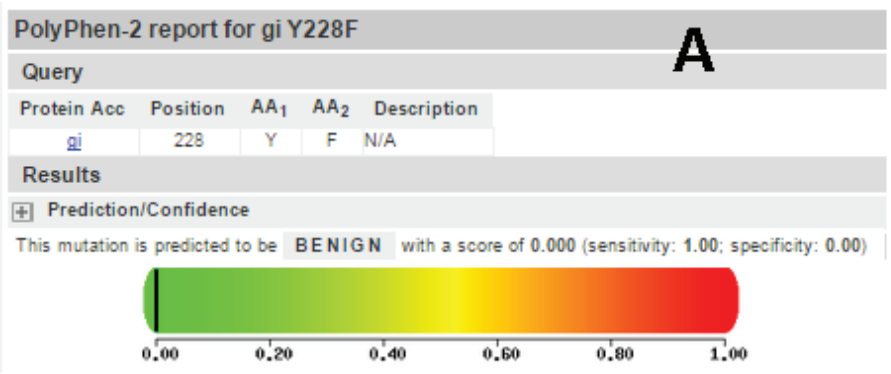

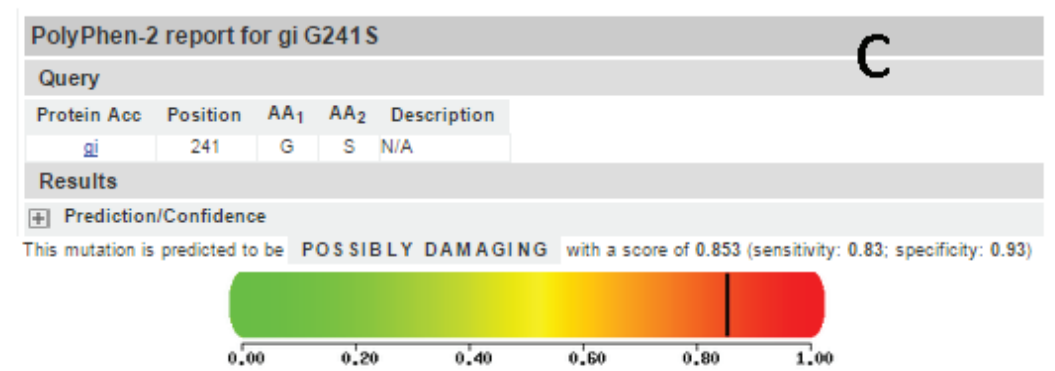

Fig.1. Resultado apresentado pelo PolyPhen: (A) SNP_683 que ocasiona alteração de tirosina (Y) para fenilalanina (F) na posição 228 da cadeia polipeptídica, (B) SNP_479 que ocasiona alteração de valina (V) para alanina (A) na posição 160 da cadeia polipeptídica e (C) SNP_721 que ocasiona alteração de uma glicina (G) para uma serina (S) na posição 241 da cadeia polipeptídica. 
com valores inferiores a 0,05. Esse autor afirmou que essa substituição de aminoácido pode ocasionar alteração na relação estrutura-função e que essas mutações podem estar associadas a doenças. Com micro-organismos esses estudos são escassos e, com o gene floR em Aeromonas são inexistentes, o que ressalta a importância desse trabalho.

Todos os nsSNPs podem potencialmente afetar a estrutura ou função das proteínas expressas e podem ter um impacto sobre doenças complexas (Nakken et al. 2007). Para verificação se esse nsSNPs vai afetar a função da proteína é necessário que haja uma avaliação mais detalhada partindo da modelagem estrutural da proteína e de estudos "in vitro".

\section{Proteína modelada codificada pelo gene floR}

Para a modelagem das proteínas codificadas pelos diferentes haplótipos, foi inicialmente realizada a modelagem da proteína referência de $A$. bestiarum com a utilização dos moldes 3wdo, 4lds e 4ja3 que já possuíam a proteína resolvida. Esse modelo foi criado para verificação de similaridade entre a proteína referência e os 3 moldes selecionados, para posterior modelagem das proteínas codificadas pelos diferentes haplótipos identificados no presente estudo. O Modeller gerou 5 modelos e foi atribuído um score, o "molpdf", onde o modelo que tinha o menor valor foi considerado como melhor modelo. A qualidade dos modelos gerados foi avaliada pelos softwares: PROCHECK, VERIFY3D e WHATIF. Os resultados obtidos no PROCHECK para a proteína referência modelada demostram no gráfico de Ramachandran que 90,8\% dos resíduos da proteína modelada estão em regiões favoráveis (Fig.2A). Os resultados obtidos no PROCHECK para o haplótipo TAA mostram que o gráfico de Ramachandran demonstra que 92,2\% dos resíduos da proteína modelada estão em regiões favoráveis (Fig.2B), para o haplótipo TTA o gráfico demonstra que $91,4 \%$ dos resíduos da proteína modelada estão em regiões favoráveis (Fig.2C) e para o haplótipo CTG o gráfico demonstra que $92,2 \%$ dos resíduos da proteína modelada estão em regiões favoráveis (Fig.2D). Esses resultados demonstram que a exatidão estereoquímica dos modelos gerados é boa. De acordo com Laskowski et al. (1993) a estrutura para ser ideal deve ter mais de $90 \%$ dos seus resíduos nas regiões vermelhas, marcada com A, B e L (regiões favoráveis).

Os resultados obtidos no VERIFY3D para a proteína referência demostraram que $69,55 \%$ dos resíduos da proteína modelada obtiveram pontuação média de 3D-1D acima ou igual a 0,2. Nas análises com o WHATIF a qualidade do empacotamento da proteína referência modelada apresentou valor médio de -1.050 sendo assim, o modelo obtido foi considerado bom. A qualidade é avaliada da seguinte forma:
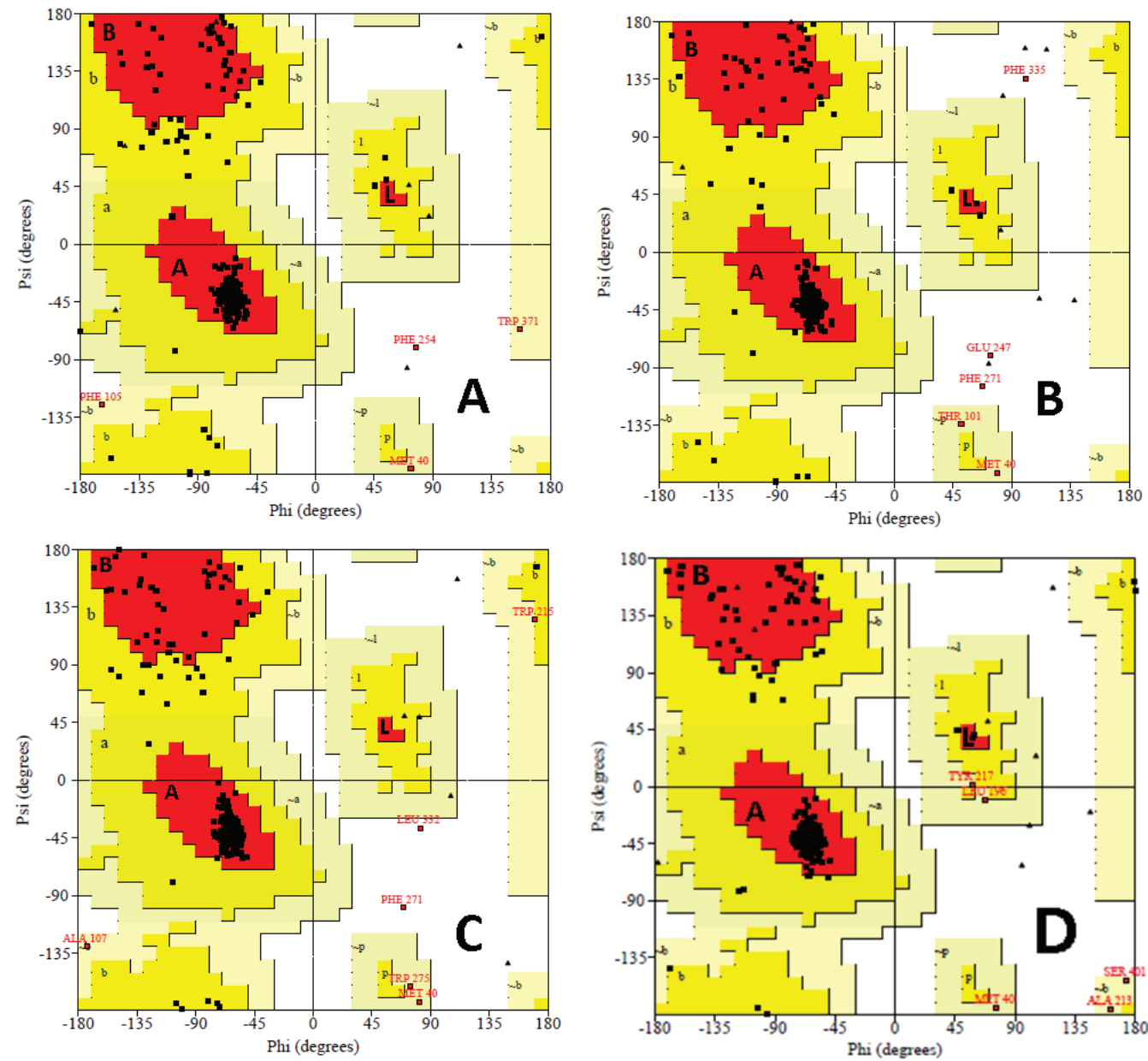

Fig.2. Gráfico de Ramachandran referente à: (A) proteína de referência do gene floR com 90,8\%, (B) haplótipos TAA com 92,2\%, (C) TTA com 91,4\% e (D) CTG com 92,2 dos resíduos da proteína modelada em regiões favoráveis (regiões marcadas em A, B e L dentro de cada quadrante). 
maior que $-0,5$ = ótimo modelo; em -0,5 = valor médio para um bom modelo; entre -1,0 e -0,5 = ainda um bom modelo; em -1,5 = ainda um bom modelo, mas com pequenos erros; em -2,0 = modelo considerado pobre; em -3,0 = modelo ruim (Vriend \& Sander 1993).

Os modelos 3D das proteínas modeladas para os três haplótipos TAA, CTG e TTA estão representados na Fig.3A,B,C e da proteína codificada pelo gene $f l o R$, modelada para A. bestiarium (proteína referência), está representada na Fig.3 (D), respectivamente (Sali \& Blundell 1993).

Os resultados obtidos no VERIFY3D para o haplótipo TAA mostraram que $79,46 \%$ dos resíduos da proteína modelada obtiveram pontuação média de 3D-1D acima ou igual a 0,2, para o haplótipo TTA $81,68 \%$ dos resíduos da proteína modelada obtiveram pontuação média de 3D-1D acima ou igual a 0,2 e para o haplótipo CTG 80,45\% dos resíduos da proteína modelada obtiveram pontuação média de 3D-1D acima ou igual a 0,2. Esses resultados demonstram que esses modelos são confiáveis em relação ao enovelamento das proteínas, onde $80 \%$ dos resíduos devem estar acima ou iguais a 0,2 (Bowie et al. 1991).

Os resultados obtidos no WHATIF para a qualidade do empacotamento do haplótipo TAA mostraram que o valor médio encontrado foi de -0,994, para o haplótipo TTA o valor médio encontrado foi de $-0,968$, para o haplótipo CTG o valor médio encontrado foi de -1,061. Esses resultados mostraram que esses modelos são considerados bons.

Os resultados do TM-align para o modelo das proteínas codificadas pelos haplótipos TAA, TTA e CTG demonstraram que essas proteínas possuem praticamente a mesma conformação da proteína referência (valores de TM-score de 0,98414, 0,98557 e 0,98400 para os haplótipos TAA, TTA e CTG, respectivamente). De acordo com Zhang \& Skolnick (2005), o TM-score é dado entre 0 e 1, com os melhores alinhamentos apresentando pontuações próximas de 1 . Pontuações próximas a 1 são dadas quando no alinhamento as regiões se apresentam ordenadas e pontuações baixas são dadas quando no alinhamento há regiões de desordem (Zhang \& Skolnick 2005). Esses resultados indicam que as mutações encontradas não provocam alterações na estrutura da proteína codificada pelo gene floR. De acordo com Nayeem et al. (2006) a conformação estrutural de uma proteína é mais conservada que sua sequência de aminoácidos durante o processo evolutivo, e que pequenas mudanças na sequência geralmente provocam sutis modificações na estrutura tridimensional.
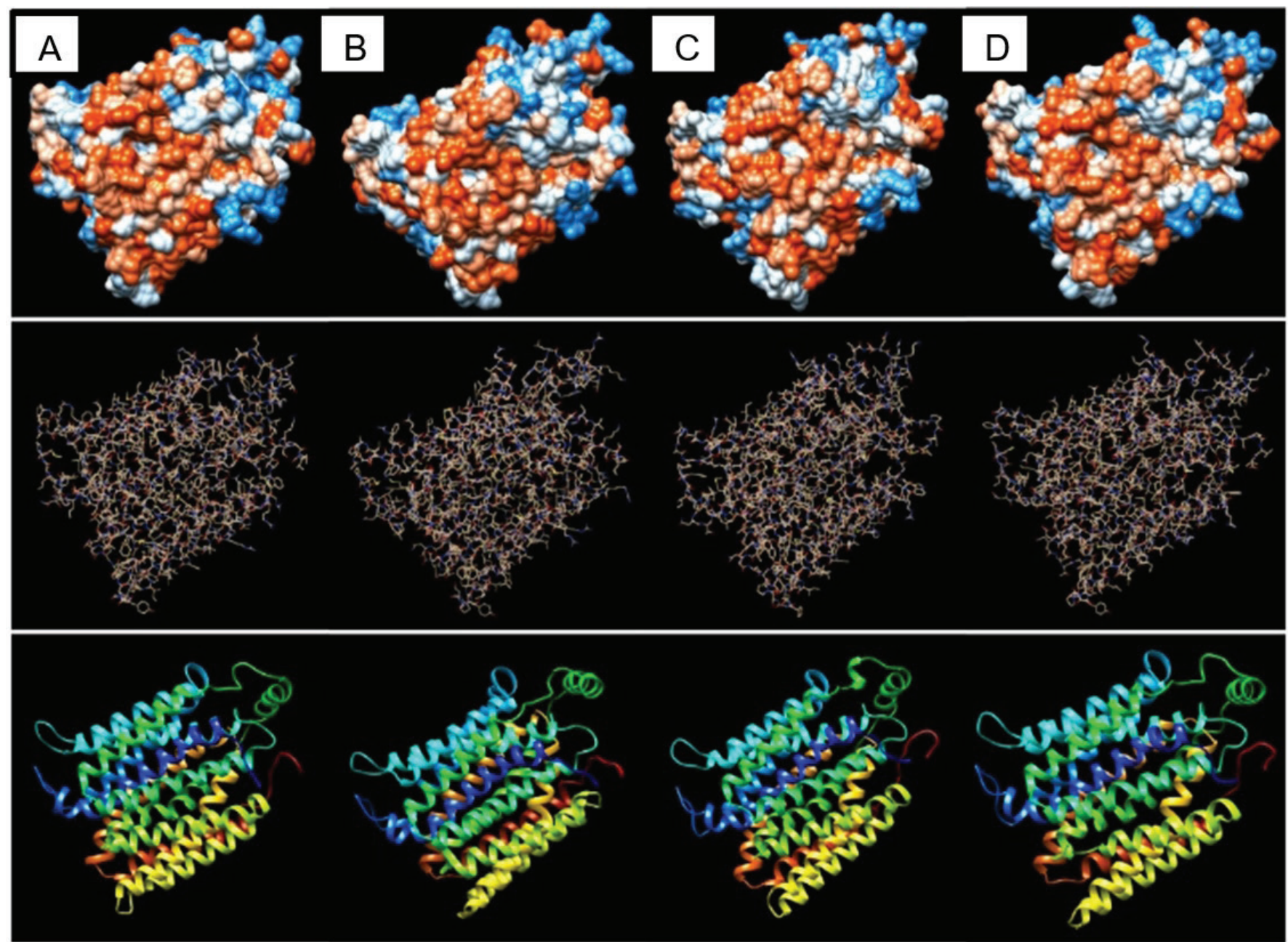

Fig.3. Proteina modelada no programa Modeller para haplótipo (A) TAA, (B) CTG, (C) TTA e (D) A. bestiarum. Estrutura 3D, atómos e ribons, respectivamente. 
Resistência dos isolados de Aeromonas spp. ao florfenicol

No presente estudo, segundo o teste de microdiluição em caldo, os 14 isolados que continham o gene floR foram resistentes ao florfenicol e 13 isolados que foram negativos para a presença do gene foram sensíveis no teste. Esses resultados comprovam que nos isolados avaliados o gene floR é o responsável pela resistência ao florfenicol e, que os SNPs detectados nesse estudo não afetam a função desse gene, fato que reforça os resultados obtidos pela modelagem das proteínas codificadas pelos diferentes haplótipos detectados. Um estudo realizado por FernándezAlarcón et al. (2010) com bacilos gram negativos isolados de peixes mostrou que todos os isolados que continham o gene floR eram resistentes ao florfenicol e também apresentavam resistência a múltiplas drogas. Testes de microdiluição em caldo de isolados de Salmonella spp. que possuíam o plasmídeo contendo o gene floR demonstraram resistência tanto para florfenicol quanto para o cloranfenicol (Doublet et al. 2004). O cloranfenicol e alguns derivados como o tianfenicol e azidamfenicol têm sido usados ao longo dos anos na medicina humana (Schwarz et al. 2004). A resistência bacteriana mediada pelo gene floR ao cloranfenicol, levanta a possibilidade de que esse antimicrobiano poderia ter selecionado anteriormente 0 gene $f l o R$, muito antes da introdução do florfenicol na medicina veterinária (Doublet et al. 2004).

Vários genes têm sido descritos pela literatura contribuindo de forma combinada para resistência ao cloranfenicol e florfenicol, como pp-flo, CMLA-like, floSt, flo, ou floR. Esses genes já foram encontrados em diferentes espécies, como: Salmonella Typhimurium, Vibrio cholerae, Escherichia coli, Photobacterium damselae subsp. Piscicida, etc. Apesar das várias designações, esses genes estão intimamente relacionados mostrando $96-100 \%$ de identidade em suas sequências de nucleotídeos e 88-100\% de identidade de sequências de aminoácidos (Schwarz et al. 2004). Os genes pp-flo, CMLA-like, floSt e flo começaram a ser descritos na literatura depois que se iniciou o uso do cloranfenicol. Após a proibição do uso desse antimicrobiano na medicina veterinária e a substituição pelo florfenicol, que é derivado do cloranfenicol, começaram a surgir relatos da resistência bacteriana através do gene floR. 0 gene floR está relacionado diretamente com a resistência ao florfenicol, como comprovado no presente estudo, e já foi descrito em bactérias de diferentes gêneros (Schwarz et al. 2004).

\section{Resistência dos isolados de Aeromonas spp. ao florfenicol na presença do Carbonil Cianeto $\mathrm{m}$-Clorofenil Hidrazona (CCCP)}

No teste com o inibidor de bomba de efluxo (CCCP) na presença do florfenicol, os três isolados testados para os três diferentes haplótipos identificados nesse estudo (TTA, TAA e CTG), que eram resistentes ao florfenicol, demostraram sensibilidade em todas as concentrações utilizadas (Quadro 4). Esse resultado pode comprovar que a resistência ao florfenicol está relacionada com a atividade de bombas de efluxo, sendo que na presença do inibidor as bactérias se tornaram sensíveis ao antimicrobiano testado (florfenicol).

De acordo com Du et al. (2004), em seu estudo utilizando o inibidor de bomba de efluxo CCCP, em isolados de Escherichia coli que tinham o gene floR e eram resistentes ao florfenicol, foi possível observar que houve um aumento rápido e significativo de florfenicol dentro da célula após o uso do CCCP. Esses autores afirmam que a resistência ao florfenicol ocorre devido à presença de bomba de efluxo. Estudos realizados por Kadlec et al. (2007) e Vecchione et al. (2009) utilizando o inibidor de bomba de efluxo Phe-Arg- $\beta$-naphthylamide (PA $\beta N$ ) em bactérias resistentes ao
Quadro 4. Referente aos 3 haplótipos testados na microdiluição em caldo com presença e ausência do inibidor CCCP

\begin{tabular}{cccc}
\hline Isolado & CBM (sem CCCP) & $\begin{array}{c}\text { CBM (com CCCP))bm } \\
\text { (com cccp) }\end{array}$ & Haplótipo \\
\hline P 1.6 & $>73,1 \mu \mathrm{g} / \mathrm{mL}$ & $<0,0085 \mu \mathrm{g} / \mathrm{mL}$ & TAA \\
35 & $>2,34 \mathrm{mg} / \mathrm{mL}$ & $<0,0085 \mu \mathrm{g} / \mathrm{mL}$ & CTG \\
G4 & $>9,14 \mu \mathrm{g} / \mathrm{mL}$ & $<0,0085 \mu \mathrm{g} / \mathrm{mL}$ & TTA
\end{tabular}

florfenicol, indicaram que essa resistência pode ser explicada pela presença de bombas de efluxo. Inibidores de bomba de efluxo vêm sendo pesquisados como alternativas terapêuticas em outros micro-organismos como Staphylococcus aureus e Pseudomonas aeruginosa (Askoura et al. 2011, Handzlik et al. 2013). Além de representar uma opção terapêutica, os inibidores de bomba de efluxo são muito importantes para detecção deste mecanismo de resistência (Van Bambeke et al. 2010). Produtos naturais têm sido explorados quando a sua capacidade de inibição de bomba de efluxo em micro-organismos. Estudos desta natureza são bastante complexos e necessitam da integração de plataformas de caracterização química, genética e de bioinformática (Tegos et al. 2011).

No presente estudo, pode ser observado também que, o inibidor de bomba de efluxo não provocou diferença de sensibilidade/resistência ao antimicrobiano florfenicol quando se comparam os três haplótipos encontrados nesse estudo. Esse resultado consolida os resultados do TM-align ao comparar as proteínas modeladas pelos haplótipos TAA, TTA e CTG que demonstrou que essas proteínas possuem praticamente a mesma conformação e também os resultados gerados pelo SIFT e PolyPhen que não demonstraram alteração de função em relação aos SNPs detectados.

\section{CONCLUSÕES}

Foi possível observar nesse estudo que a resistência ao florfenicol em Aeromonas spp. pode ser explicada pela presença do gene floR.

Os isolados de Orecohromis niloticus e Lophiosilurus alexandri avaliados apresentaram mutações no gene $f l o R$, mas essas mutações não estão envolvidas com alteração de estrutura e função da proteína codificada por esse gene.

\section{REFERÊNCIAS}

Adzhubei I.A., Schmidt S., Peshkin L., Ramensky V.E., Gerasimova A., Bork P., Kondrashov A.S. \& Sunyaev S.R. 2010. A method and server for predicting damaging missense mutations. Nat. Methods 7(4):248-249. http://dx.doi. org/10.1038/nmeth0410-248. PMid:20354512.

Askoura M., Mattawa W., Abujamel T. \& Taher I. 2011. Efflux pump inhibitors (EPIs) as new antimicrobial agents against Pseudomonas aeruginosa. Libyan J. Med. 6(1):5870. http://dx.doi.org/10.3402/ljm.v6i0.5870. PMid:21594004.

Bao L. \& Cui Y. 2005. Prediction of the phenotypic effects of non-synonymous single nucleotide polymorphisms using structural and evolutionary Information. Bioinformatics 21(10):2185-2190. http://dx.doi.org/10.1093/ bioinformatics/bti365. PMid:15746281.

Barton B.A. \& Iwama G.K. 1991. Physiological changes in fish from stress in aquaculture with emphasis on the response and effects of corticosteroids. Annu. Rev. Fish Dis. 1:3-26. http://dx.doi.org/10.1016/0959-8030(91)90019-G.

Baym M., Stone L.K. \& Kishony R. 2016. Multidrug evolutionary strategies to reverse antibiotic resistance. Science 351(6268):aad3292. PMid:26722002. 
Beaz-Hidalgo R. \& Figueras M.J. 2013. Aeromonas spp. whole genomes and virulence factors implicated in fish disease. J. Fish Dis. 36(4):371-388. http://dx.doi.org/10.1111/jfd.12025. PMid:23305319.

Blast-Protein 2015. Disponível em <http://blast.ncbi.nlm.nih.gov/Blast.cgi> Acesso em 10 out. 2015.

Bowie J.U., Luthy R. \& Eisenberg D. 1991. A method to identify protein sequence that fold into known tree-dimensional structure. Science 253(5016):164170. http://dx.doi.org/10.1126/science.1853201. PMid:1853201.

Capriotti E. \& Altman R.B. 2011. Improving the prediction of disease-related variants using protein three-dimensional structure. BMC Bioinformatics 12(Suppl.4):S3. http://dx.doi.org/10.1186/1471-2105-12-S4-S3. PMid:21992054.

CLSI (Clinical and Laboratory Standards Institute) 2014. Methods for Broth Dilution Susceptibility Testing of Bacteria Isolated From Aquatic Animals. 2nd Ed. CLSI Document CLSI VET04-A2.

Dallaire-Dufresne S., Tanaka K.H., Trudel M.V., Lafaille A. \& Charette S.J. 2014. Virulence, genomic features, and plasticity of Aeromonas salmonicida subsp. salmonicida, the causative agent of fish furunculosis. Vet. Microbiol. 169(1/2):1-7. http://dx.doi.org/10.1016/j.vetmic.2013.06.025. PMid:23890675.

Doublet B., Carattoli A., Whichard J.M., White D.G., Baucheron S., ChaslusDancla E. \& Cloeckaert A. 2004. Plasmid mediated florfenicol and ceftriaxone resistance encoded by the floR and blaCMY-2 genes in Salmonella enterica serovars Typhimurium and Newport isolated in the United States. FEMS Microbiol. Lett. 233(2):301-305. http://dx.doi.org/10.1111/j.1574-6968.2004. tb09496.x. PMid:15063500.

Du X., Xia C., Shen J., Wu B. \& Shen Z. 2004. Characterization of florfenicol resistance among calf pathogenic Escherichia coli. FEMS Microbiol. Lett. 236(2):183-189. http://dx.doi.org/10.1111/j.1574-6968.2004.tb09645.x. PMid:15251195.

Ewing B. \& Green P. 1998. Base-calling of automated sequencer traces using phred. II: error probabilities. Genome Res. 8(3):186-194. http://dx.doi. org/10.1101/gr.8.3.186. PMid:9521922.

Ewing B., Hillier L., Wendl M.C. \& Green P. 1998. Base-calling of automated sequencer traces using phred. I: accuracy assessment. Genome Res. 8(3):175-185. http://dx.doi.org/10.1101/gr.8.3.175. PMid:9521921.

Fernández-Alarcón C., Miranda C.D., Singer R.S., López Y., Rojas R., Bello H., Domínguez M. \& González-Rocha G. 2010. Detection of the floR gene in a diversity of florfenicol resistant gram-negative bacilli from freshwater salmon farms in Chile. Zoonoses Public Health 57(3):181-188. http:// dx.doi.org/10.1111/j.1863-2378.2009.01243.x. PMid:19538451.

Ghatak S., Agarwal R.K. \& Bhilegaonkar K.N. 2007. Species identification of clinically important Aeromonas spp. By restriction fragment length polymorphism of 16S rDNA. Lett. Appl. Microbiol. 44(5):550-554. http:// dx.doi.org/10.1111/j.1472-765X.2006.02104.x. PMid:17451524.

Godoy D.T., Mian G.F., Zanolo R., Yuhara T.Y., Faria F.C. \& Figueiredo H.C.P. 2008. Patterns of resistance to florfenicol and bicyclomycin in Brazilian strains of motile aeromonads. Aquaculture 285(1-4):255-259. http:// dx.doi.org/10.1016/j.aquaculture.2008.08.014.

Gordon L., Cloeckaert A., Doublet B., Schwarz S., Bouju-Albert A., Ganière J.P., Le Bris H., Le Flèche-Matéos A. \& Giraud E. 2008. Complete sequence of the floR-carrying multiresistance plasmid pAB5S9 from freshwater Aeromonas bestiarum. J. Antimicrob. Chemother. 62(1):65-71. http:// dx.doi.org/10.1093/jac/dkn166. PMid:18413319.

Goswami A.M. 2015. Structural modeling and in silico analysis of nonsynonymous single nucleotide polymorphisms of human 3ß-hydroxysteroid dehydrogenase type 2. Meta Gene 5:162-172. http://dx.doi.org/10.1016/j. mgene.2015.07.007. PMid:26288759.

Haenen O.L.M., Evans J.J. \& Berthe F. 2013. Bacterial infections from aquatic species: potential for and prevention of contact zoonoses. Rev. Sci. Tech. 32(2):497-507. http://dx.doi.org/10.20506/rst.32.2.2245. PMid:24547653.

Handzlik J., Matys A. \& Kieć-Kononowicz K. 2013. Recent advances in multidrug resistance (MDR) efflux pump inhibitors of gram-positive bacteria
S. aureus. Antibiotics, Basel, 2(1):28-45. http://dx.doi.org/10.3390/ antibiotics2010028. PMid:27029290.

Huang X. \& Madan A. 1999. CAP3: A DNA Sequence Assembly Program. Genome Res. 9(9):868-877. http://dx.doi.org/10.1101/gr.9.9.868. PMid:10508846.

Jalal S., Ciofu O., Høiby N., Gotoh N. \& Wretlind B. 2000. Molecular mechanisms of fluoroquinolone resistance in Pseudomonas aeruginosa isolates from cystic fibrosis patients. Antimicrob. Agents Chemother. 44(3):710-712. http://dx.doi.org/10.1128/AAC.44.3.710-712.2000. PMid:10681343.

Janda J.M. \& Abbott S.L. 2010. The Genus Aeromonas: taxonomy, pathogenicity, and infection. Clin. Microbiol. Rev. 23(1):35-73. http://dx.doi.org/10.1128/ CMR.00039-09. PMid:20065325.

Kadlec K., Kehrenberg C. \& Schwarz S. 2007. Efflux-mediated resistance to florfenicol and/or chloramphenicol in Bordetella bronchiseptica: identification of a novel chloramphenicol exporter. J. Antimicrob. Chemother. 59(2):191196. http://dx.doi.org/10.1093/jac/dkl498. PMid:17224413.

Larkin M.A., Blackshields G., Brown N.P., Chenna R., Mcgettigan P.A., Mcwilliam H., Valentin F., Wallace I.M., Wilm A., Lopez R., Thompson J.D., Gibson T.J. \& Higgins D.G. 2007. Clustal W and Clustal X version 2.0. Bioinformatics 23(21):2947-2948. http://dx.doi.org/10.1093/bioinformatics/btm 404 . PMid:17846036.

Laskowski R.A., Macarthur M.W., Moss D.S. \& Thornton J.M. 1993. Procheck: a program to check the stereochemical quality of protein structures. J. Appl. Cryst. 26(2):283-291. http://dx.doi.org/10.1107/S0021889892009944.

Lehninger A.L. 2006. Lehninger Princípios da Bioquímica. 4⿳ạa ed. Savier, São Paulo. 1232p.

Li F., Wang W., Zhu Z., Chen A., Du P., Wang R., Chen H., Hu Y., Li J., Kan B. \& Wang D. 2015. Distribution, virulence-associated genes and antimicrobial resistance of Aeromonas isolates from diarrheal patients and water, China. J. Infect. 70(6):600-608. http://dx.doi.org/10.1016/j.jinf.2014.11.004. PMid:25447712.

Lynch A.S. 2006. Efflux systems in bacterial pathogens: An opportunity for therapeutic intervention? An industry view. Biochem. Pharmacol. 71(7):949956. http://dx.doi.org/10.1016/j.bcp.2005.10.021. PMid:16290174.

Nakken S., Alseth I. \& Rognes T. 2007. Computational prediction of the effects of non-synonymous single nucleotide polymorphisms in human DNA repair genes. Neuroscience 145(4):1273-1279. http://dx.doi.org/10.1016/j. neuroscience.2006.09.004. PMid:17055652.

Nayeem A., Sitkoff D. \& Krystek Jr S.A. 2006. Comparative study of available software for high-accuracy homology modeling: From sequence alignments to structural models. Protein Sci.15(4):808-824. http://dx.doi.org/10.1110/ ps.051892906. PMid:16600967.

NCBI 2016. Disponível em <http://www.ncbi.nlm.nih.gov/> Acesso em 10 fev. 2016.

Ng P.C. \& Henikoff S. 2001. Predicting deleterious amino acid substitutions. Genome Res. 11(5):863-874. http://dx.doi.org/10.1101/gr.176601. PMid:11337480.

Ng P.C. \& Henikoff S. 2003. SIFT: predicting amino acid changes that affect protein function. Nucleic Acids Res. 31(13):3812-3814. http://dx.doi. org/10.1093/nar/gkg509. PMid:12824425.

Pandiyan P., Balaraman D., Thirunavukkarasu R., George E.G.J., Subaramaniyan K., Manikkam S. \& Sadayappan B. 2013. Probiotics in aquaculture. Drug Invention Today 5(1):55-59. http://dx.doi.org/10.1016/j.dit.2013.03.003.

Park B.K., Lim J.H., Kim M.S., Hwang W.H. \& Yun H.I. 2008. Pharmacokinetics of florfenicol and its metabolite, florfenicol amine, in dogs. Res. Vet. Sci. 84(1):85-89. http://dx.doi.org/10.1016/j.rvsc.2007.04.001. PMid:17570454.

PDB 2016. Disponível em <http://www.rcsb.org/pdb/home/home.do> Acesso em 10 fev. 2016. 
Piotrowska M. \& Popowska M. 2014. The prevalence of antibiotic resistance genes among Aeromonas species in aquatic environments. Ann. Microbiol. 64(3):921-934. http://dx.doi.org/10.1007/s13213-014-0911-2.

Prosite 2016. Disponível em <http://prosite.expasy.org/> Acesso em 10 fev. 2016

Quinn P.J., Carter M.E., Markey B. \& Carter G.R. 1994. Clinical Veterinary Medicine. London. 648p.

Sá M.C.A., Gouveia G.V., Krewer C.C., Veschi J.L.A., Mattos-Guaraldi A.L. \& Costa M.M. 2013. Distribution of PLD and FagA, B, C and D genes in Corynebacterium pseudotuberculosis isolates from sheep and goats with caseus lymphadenitis. Genet. Mol. Biol. 36(2):265-268. http://dx.doi org/10.1590/S1415-47572013005000013. PMid:23885209.

Sali A. \& Blundell T.L. 1993. Comparative protein modelling by satisfaction of spatial restraints. J. Mol. Biol. 234(3):779-815. http://dx.doi.org/10.1006/ jmbi.1993.1626. PMid:8254673.

Schwarz S., Kehrenberg C., Doublet B. \& Cloeckaert A. 2004. Molecular basis of bacterial resistance to chloramphenicol and florfenicol. FEMS Microbiol. Rev. 28(5):519-542. http://dx.doi.org/10.1016/j.femsre.2004.04.001. PMid:15539072.

Swiss-Model 2015. Disponível em <http://swissmodel.expasy.org/> Acesso em 10 out. 2015.

Tamura K., Peterson D., Peterson N., Stecher G., Nei M. \& Kumar S. 2011. MEGA5: Molecular evolutionary genetics analysis using maximum likelihood, evolutionary distance, and maximum parsimony methods. Mol. Biol. Evol. 28(10):2731-2739. http://dx.doi.org/10.1093/molbev/ msr121. PMid:21546353.

Tegos G.P, Haynes M., Strouse J.J., Khan M.M.T., Bologa C.G., Oprea T.I. \& Sklar L.A. 2011. Microbial efflux pump inhibition: tactics and strategies. Curr. Pharm. Des.17(13):1291-1302. http://dx.doi.org/10.2174/138161211795703726. PMid:21470111.

Teng S., Madej T., Panchenko A. \& Alexov E. 2009. Modeling effects of human single nucleotide polymorphisms on protein-protein interactions. Biophys. J. 96(6):2178-2188. http://dx.doi.org/10.1016/j.bpj.2008.12.3904. PMid:19289044.
Van Bambeke F., Pagès J.M. \& Lee V.J. 2010. Inhibitors of bacterial efflux pumps as adjuvants in antibacterial therapy and diagnostic tools for detection of resistance by efflux. Front. Anti-Infective Drug Discov. 1:138-175.

Vecchione J.J., Alexander Jr B.J.R. \& Sello J.K. 2009. Two distinct major facilitator superfamily drug efflux pumps mediate chloramphenicol resistance in Streptomyces coelicolor. Antimicrob. Agents Chemother. 53(11):4673-4677. http://dx.doi.org/10.1128/AAC.00853-09. PMid:19687245.

Verner-Jeffreys D.W., Welch T.J., Schwarz T., Pond M.J., Woodward M.J., Haig S.J., Rimmer G.S.E., Roberts E., Morrison V. \& Baker-Austin C. 2009. High prevalence of multidrug-tolerant bacteria and associated antimicrobial resistance genes isolated from ornamental fish and their carriage water. PloS one 4(12):e8388. http://dx.doi.org/10.1371/journal.pone.0008388. PMid:20027306.

Vogwill T. \& Maclean C. 2015. The genetic basis of the fitness costs of antimicrobial resistance: a meta-analysis approach. Evol. Appl. 8(3):284295. http://dx.doi.org/10.1111/eva.12202. PMid:25861386.

Vriend G. \& Sander C. 1993. Quality control of protein models: Directional atomic contact analysis. J. Appl. Cryst. 26(1):47-60. http://dx.doi. org/10.1107/S0021889892008240.

Wang H., Dzink-Fox J.L., Chen M. \& Levy S.B. 2001. Genetic characterization of highly fluoroquinolone-resistant clinical Escherichia coli strains from China: role ofacrR mutations. Antimicrob. Agents Chemother. 45(5):1515-1521. http://dx.doi.org/10.1128/AAC.45.5.1515-1521.2001. PMid:11302820.

Weigel M.L., Anderson G.J., Facklam R.R. \& Tenover F.C. 2001. Genetic analyses of mutations contributing to fluoroquinolone resistance in clinical isolates of Streptococcus pneumoniae. Antimicrob. Agents Chemother. 45(12):3517-3523. http://dx.doi.org/10.1128/AAC.45.12.3517-3523.2001. PMid:11709333.

Welch T.J., Evenhuis J., White D.G., Mcdermott P.F., Harbottle H., Miller R.A., Griffin M. \& Wise D. 2009. IncA/C plasmid-mediated florfenicol resistance in the catfish pathogen Edwardsiella ictaluri. Antimicrob. Agents Chemother. 53(2):845-846. http://dx.doi.org/10.1128/AAC.01312-08. PMid:19029319.

Zhang Y. \& Skolnick J. 2005. TM-align: a protein structure alignment algorithm based on the TMscore. Nucleic Acids Res. 33(7):2302-2309. http://dx.doi. org/10.1093/nar/gki524. PMid:15849316. 